Chronic Obstructive Pulmonary Diseases:

Journal of the COPD Foundation

COOND

\author{
Original Research
}

\title{
Characteristics of COPD Patients Using United States Emergency Care or Hospitalization
}

\author{
Suchit D. Kumbhare, MBBS, MSCR ${ }^{1}$ Tatsiana Beiko, $\mathrm{MD}^{1}$ Susan R. Wilcox, $\mathrm{MD}^{1,2}$ Charlie Strange, $\mathrm{MD}^{1}$
}

\begin{abstract}
Rationale: Several chronic obstructive pulmonary disease (COPD) studies have evaluated risk factors for emergency department (ED) visits or hospitalizations, and found insufficient data available about social and demographic factors that drive these behaviors. This U.S. study was designed to describe the characteristics of COPD patients with ED visits or a hospitalization and to investigate how often common COPD comorbidities are present in these individuals.
\end{abstract}

Methods: Data for 7180 COPD patients regarding demographic factors, comorbidities, smoking status, and ED visits or hospitalization was obtained from the 2012 Behavioral Risk Factor Surveillance System (BRFSS) survey. Logistic regression analysis was used to adjust demographic factors and smoking status to model the correlation between patients with ED visits or hospitalizations and morbidities generating odds ratios (OR) and confidence intervals (CI).

Results: Among diagnosed COPD patients in the BRFSS, $16.5 \%$ had ED visits or hospitalization in the previous year. These individuals were younger, had a lower socio-economic status (lower education, lower income, and more often unemployed) and $23.4 \%$ of the individuals could not visit a doctor because of the financial difficulties compared to $16.7 \%$ who had no visit ( $p<0.0001$ for all comparisons). The prevalence of comorbidities was higher in those with ED visits or hospitalization compared to those without.

Conclusion: In a population representative of COPD patients, lower socio-economic status and higher comorbidities are associated with ED visits or hospitalization. Studies are needed to further elucidate the complex relationship between COPD, comorbidities, and ED visits or hospitalization.

\footnotetext{
Abbreviations: chronic obstructive pulmonary disease, COPD; emergency department, ED; Behavioral Risk Factor Surveillance System, BRFSS; odds ratio, OR; confidence intervals, CI; Centers for Disease Control and Prevention, CDC; body mass index, BMI; cardiovascular disease, CVD

Funding Support: None.

Date of Acceptance: December 9, 2015

Citation: Kumbhare SD, Beiko T, Wilcox SR, Strange C. Characteristics of COPD patients using United States emergency care or hospitalization. Chronic Obstr Pulm Dis (Miami). 2016; 3(2):539-548. doi: http://dx.doi.org/10.15326/jcopdf.3.2.2015.0155
}

1 Division of Pulmonary, Critical Care, Allergy and Sleep Medicine, Department of Medicine, Medical University of South Carolina, Charleston

2 Division of Emergency Medicine, Department of Medicine, Medical University of South Carolina, Charleston

\section{Address correspondence to:}

Charlie Strange, MD

Division of Pulmonary and Critical Care Medicine

Medical University of South Carolina

96 Jonathan Lucas St. 812 CSB

Charleston, SC, 29425

Phone: 843-792-3174

strangec@musc.edu

\section{Keywords:}

COPD; hospitalization; emergency department; ED; emergency room; ER; comorbidity; body mass index; BMI; Behavioral Risk Factor Surveillance System; BRFSS; prevalence

\section{Introduction}

Chronic obstructive pulmonary disease (COPD) is a major cause of chronic morbidity and mortality throughout the world. It is the third leading cause of death in the United States. ${ }^{1,2}$ The prevalence of COPD ranges from $8 \%$ to $20 \%$ worldwide and is the only disease with increasing death rates, rising by $16 \%$ since $2002 .^{3}$ 
COPD exacerbations impact the natural progression of disease, are responsible for the majority of costs, and are associated with high mortality. ${ }^{4}$

COPD patients often need emergency department (ED) visits or hospital admissions because of acute exacerbations that may progress to respiratory failure. Over the past decade, studies have defined the major predictors of exacerbation to be past exacerbations. ${ }^{5}$ However, the majority of exacerbations do not present to the ED or to hospitals. It remains unknown how many of these visits also are associated with deterioration of other conditions. ${ }^{6}$

Hospitalizations associated with COPD continue to be a significant part of spending of health care resources. In 2010, the health cost associated with COPD in the United States was 50 billion dollars. ${ }^{4}$ These costs increase as the severity and exacerbation frequency of COPD becomes worse. The spending associated with hospitalization accounts for more than $70 \%$ of COPD-related medical care costs. ${ }^{7}$ Minimizing the number of preventable hospitalizations could lead to cost reduction ${ }^{8,9}$ and allocation of the resources to preventive care in COPD.

COPD often coexists with other systemic comorbid diseases, such as cardiovascular disease, hypertension, osteoporosis, neuropsychiatric conditions, arthritis, and diabetes mellitus. ${ }^{10}$ These comorbidities have shared risk factors with COPD, and can be considered to influence one another and affect mortality. ${ }^{11}$ These comorbidities impact patients' health status and interfere with COPD management. ${ }^{1}$ However, there is limited population-based epidemiologic data on the COPD patients who use the emergency department or get hospitalized for their disease.

This study was designed to describe the population based on socio-demographic characteristics of the COPD patients with ED visits or hospitalization and to determine their prevalence of common comorbidities.

\section{Methods}

This study used data collected by the Centers for Disease Control and Prevention (CDC). The Behavioral Risk Factor Surveillance system (BRFSS) survey was conducted in 2012 from 50 states and the District of Columbia and U.S. territories using telephone interviews. Details of the BRFSS and the modules used in the study are found in the online supplement. The core module of the 2012 BRFSS collected information on socio-demographic characteristics (age, sex, race, marital status, height, weight, exercise, disability, and health insurance), and chronic diseases (including myocardial infarction, coronary heart disease/ angina, cancer, stroke, depression, arthritis, kidney disease, and diabetes). Eleven states (Arizona, Connecticut, Illinois, Michigan, Minnesota, Mississippi, Montana, Nevada, Oregon, South Carolina, and Tennessee) elected to collect data on an optional COPD module used for this analysis. We chose to limit the analysis to individuals aged 35 or over to lessen respondents with asthma. Smoking was characterized as a categorical variable for current, past, or never smokers.

A history of COPD was defined as an affirmative response to the following question: "Have you ever been told by your physician that you have chronic obstructive pulmonary disease or COPD, emphysema or chronic bronchitis?" We stratified the characteristics of COPD patients on the basis of the ED visits or hospitalization status over the 1 year prior to the survey from the question: "Have you had to visit an emergency room or be admitted to the hospital in the past 12 months because of your COPD, chronic bronchitis, or emphysema?"

\section{Statistical Analysis}

We described the distribution of demographic factors for the patients in the study cohort aged $\geq 35$ years based on ED visits or hospitalization status. First, we tested for unadjusted associations between the variables and the status of ED visits or hospitalization using Chisquare test or t-test, as appropriate. The value $p<0.1$ was utilized for assessing significance for univariate models and determining potential factors to include in multiple logistic regression where $p<0.05$ was considered significant. A multinomial logistic regression model then examined the association between the ED visits or hospitalization and individual comorbidities adjusting for demographic factors and smoking status. To facilitate interpretation, the results of the analysis were expressed as an odds ratio (OR) and associated $95 \%$ confidence interval (95\% CI) for estimation of the prevalence of comorbidities. Statistical analysis was performed using SAS 9.4 package for Windows (SAS Institute Inc., Cary, NC, USA).

\section{Results}

Of 90,851 respondents from 11 states in the United States, 7755 (8.5\%) were diagnosed with COPD and 
completed the COPD module. We analyzed participants with age $\geq 35$ years and those without missing responses (89.4\%). Of these, 1131(16.3\%) reported an ED visit or hospitalization (Figure 1).

Unexpectedly, the COPD patients who had ED visits or hospitalization were younger ( $64.6 \pm 12.2$ years) compared to those without $(66.1 \pm 11.8$ years, $p<0.001)$. This difference was driven by a higher proportion of individuals > age 65 years who did not have an ED visit or hospitalization as depicted in Figure 2. Although there is a female preponderant response to the BRFSS, there was no significant difference in gender between those with COPD-related ED visits or hospitalization and those without $(p=0.49)$ (Table 1$)$.

In the analysis comparing race, non-Hispanic whites (80.6\%) were the largest number of participants in the study despite oversampling efforts to more closely match the U.S. census by BRFSS methodology. The risk of ED visits or hospitalization was highest in non-Hispanic black individuals compared to the nonHispanic whites [OR 2.00, 95\% CI (1.65-2.42)]. We also found high rates of ED visits or hospitalization in Hispanics compared to non-Hispanic whites [OR 1.61, 95\% CI (1.06-2.43)].

Comparing education between the 2 groups, the individuals who graduated from high school [OR 0.70, 95\% CI (0.58-0.83)], attended technical college [OR $0.72,95 \%$ CI (0.60-0.87)], or graduated from college [OR 0.55, 95\% CI (0.44-0.68)] had a lower risk of ED visits or hospitalization compared to those without any of these educational achievements. The ED visit or hospitalization experience for those who were divorced or widowed or separated was higher (55.9\%) compared to those who were not $(50.5 \%)(p=0.0008)$. The patients with COPD who had an ED visit or hospitalization had lower income $(p<0.0001)$ and employment $(p<0.0001)$

\section{Figure 1. Flowchart for the Respondents Included in the Study}

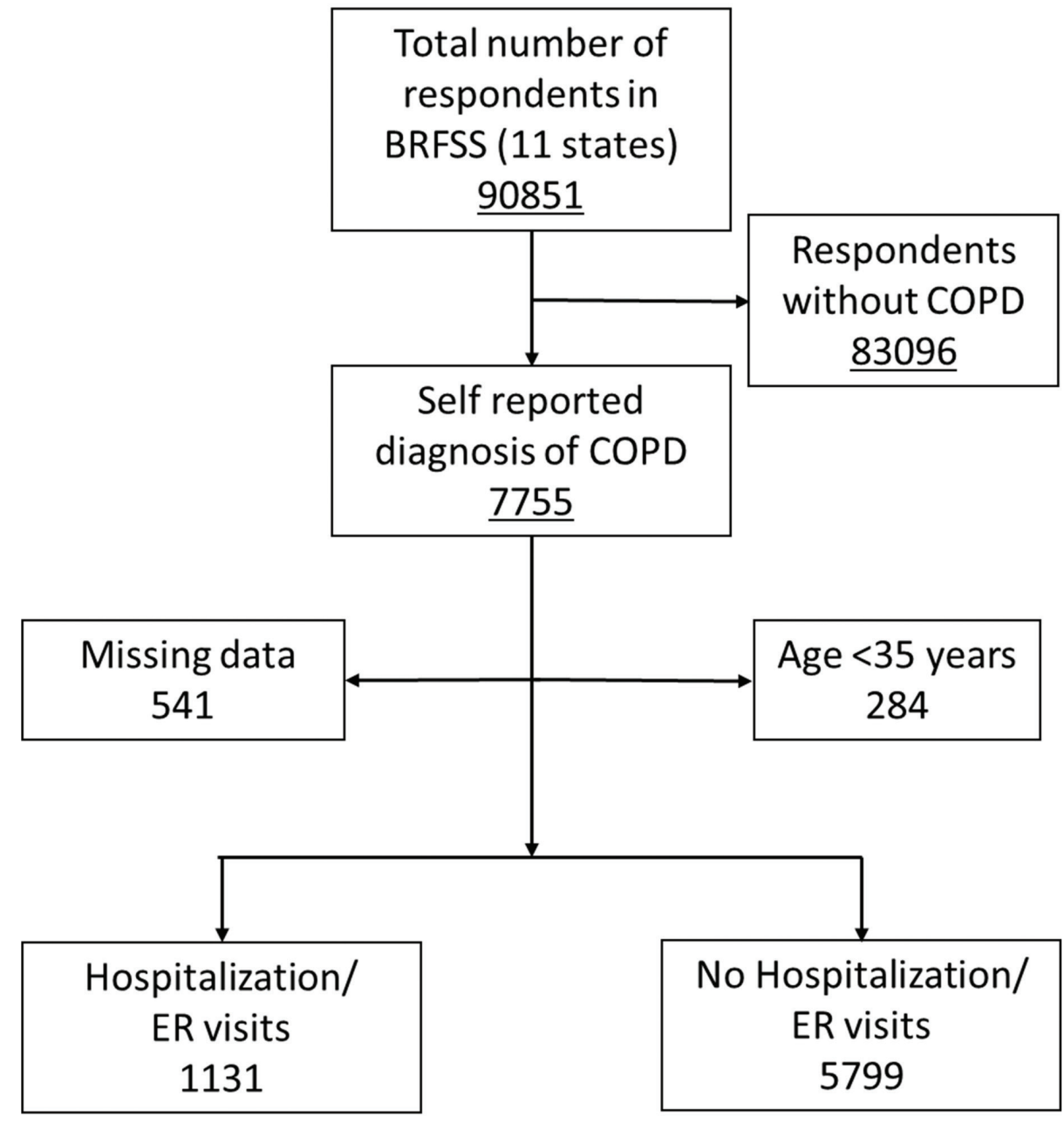




\section{Figure 2. Prevalence of ED Visits or Hospitalization: Region of United States and Age}
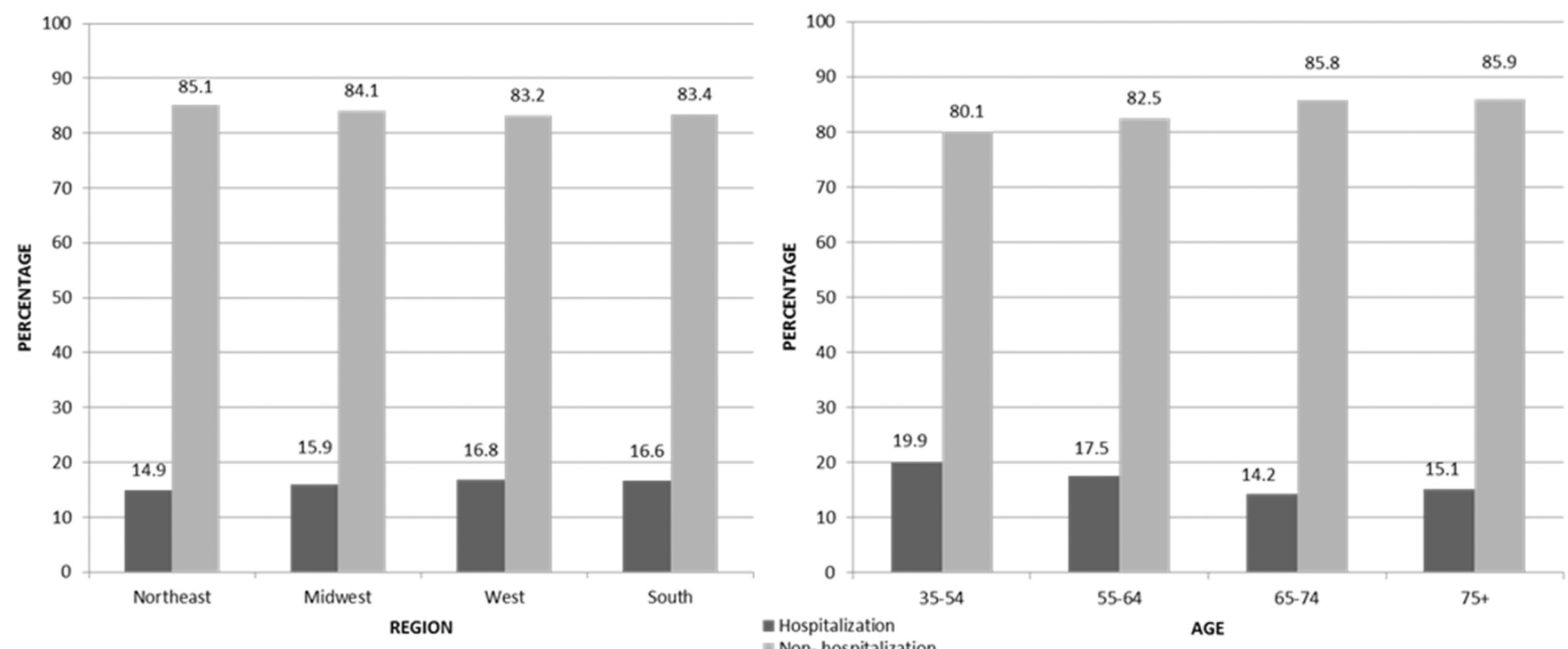

The prevalence of ED visits or hospitalization in COPD patients was higher in the Southern and Western regions of the United States. The highest prevalence occurred in individuals aged 35-54 years.

compared to those without. Interestingly, there was no significant difference in ED visits or hospitalization status by smoking category ( $p=0.1091$ ) (Table 1 ).

Health insurance was present for $91.7 \%$ and $92.0 \%$ of the cohorts and included prepaid plans such as health maintenance organizations and government plans such as Medicare, Medicaid, or the Indian Health Service. Although the health care coverage was similar, a higher proportion of individuals with ED visits or hospitalization (23.4\%) reported that they could not visit a doctor because of financial difficulties compared to those without $(16.7 \%)(p<0.0001)$. The ED visits or hospitalization rate was higher in western (16.8\%) and southern regions (16.6\%) of the United States when compared to the northeast region (14.9\%) (Figure 2). Further evaluation of disability status revealed that the individuals with ED visits or hospitalization had more disability when compared to those without hospitalization or ED visits $(79.0 \%$ versus $60.9 \%$, $p<0.0001$ ).

Table 2 shows the odds ratio for ED visits or hospitalizations was higher if the COPD patient also had one of the listed common comorbidities. Arthritis was the most frequent comorbidity, present among those who visited an ED or had a hospitalization (71.5\% versus $64.1 \%$ for those without an ED visit or hospitalization, $p<0.0001)$. Kidney disease was the least frequent comorbidity in COPD $(12.1 \%$ versus $8.3 \%$, $p<0.0001)$. Other common comorbidities reported in the BRFSS included coronary heart disease/angina (30.7\% versus $19.8 \%, p<0.0001)$, stroke $(16.7 \%$ versus $11.2 \%$, $p<0.0001)$, cancer $(22.0 \%$ versus $17.9 \%, p=0.0001)$, depression (46.7\% versus $35.8 \%, p<0.0001$ ), and diabetes (29.7\% versus $23.6 \%, p=0.0122)$. Figure 3 illustrates that the risk of comorbidities is higher in those who had ED visits or hospitalizations. Differences in the ED visits or hospitalization cohort were also found in low and high body mass index (BMI) categories (Figure 4).

\section{Discussion}

Hospital utilization generates the majority of COPDrelated health care expenses. ${ }^{12}$ Identifying patients who use the ED or hospital is clinically important, since mortality increases with the frequency of exacerbations. ${ }^{13}$ Because most current data about COPD emergency care is derived from single hospital system databases, this population-based study provides a more comprehensive picture of the sociodemographic factors and comorbidities of these COPD patients across the United States.

Most striking were the demographic differences between the emergency care and non-emergency care populations. Although older age is considered a risk 


\section{Table 1. Demographic Characteristics of the COPD Patients Who Visited or Did Not Visit an Emergency Department or Hospital in the Previous Year}

\begin{tabular}{|c|c|c|c|}
\hline Characteristic & $\begin{array}{l}\text { spitalization/ } \\
\text { ED Visits } \\
(N=1131)\end{array}$ & $\begin{array}{c}\text { No Hospitalization/ } \\
\text { ED Visits } \\
(\mathrm{N}=5799)\end{array}$ & p Value \\
\hline Age (years, mean \pm S.D) & $64.6 \pm 12.2$ & $66.1 \pm 11.8$ & $<0.0001$ \\
\hline Gender, Males (N, $(\%))$ & $377(33.3)$ & $2016(34.7)$ & 0.3544 \\
\hline \multicolumn{4}{|l|}{ Race } \\
\hline White, non-Hispanic & $834(73.8)$ & $4744(81.9)$ & \multirow{5}{*}{$<0.0001$} \\
\hline Black, non-Hispanic & $165(14.6)$ & $470(8.1)$ & \\
\hline Other race, non-Hispanic & $59(5.2)$ & 192(3.3) & \\
\hline Multiracial, non-Hispanic & $30(2.7)$ & $198(3.4)$ & \\
\hline Hispanic & $30(2.7)$ & $106(1.8)$ & \\
\hline \multicolumn{4}{|l|}{ Education } \\
\hline Did not graduate high school & $238(21.0)$ & $878(15.1)$ & \multirow{4}{*}{$<0.0001$} \\
\hline Graduated from high school & $401(35.5)$ & $229(36.7)$ & \\
\hline Attended technical college or school & $324(28.7)$ & $1664(28.7)$ & \\
\hline Graduated from college & $166(14.7)$ & 1123(19.4) & \\
\hline \multicolumn{4}{|l|}{ Marital Status } \\
\hline Married & $393(34.8)$ & $501(8.7)$ & \multirow{3}{*}{0.0008} \\
\hline Never married & 104(9.2) & $2914(50.5)$ & \\
\hline Divorced / widowed / separated & $631(55.9)$ & $2356(40.8)$ & \\
\hline \multicolumn{4}{|l|}{ Income } \\
\hline$<\$ 15000$ & $337(29.8)$ & $1201(20.7)$ & \multirow{5}{*}{$<0.0001$} \\
\hline$\$ 15000-25000$ & $305(27.0)$ & $1429(24.6)$ & \\
\hline$\$ 25000-35000$ & $107(9.5)$ & $723(12.5)$ & \\
\hline$\$ 35000-50000$ & $97(8.6)$ & $661(11.4)$ & \\
\hline$>\$ 50000$ & 125(11.1) & $986(17.0)$ & \\
\hline \multicolumn{4}{|l|}{ Employment } \\
\hline Employed & 130(11.6) & 1124(19.5) & \multirow{3}{*}{$<0.0001$} \\
\hline Homemaker/ student & $629(5.5)$ & $319(5.5)$ & \\
\hline Unemployed & 933(82.9) & $4333(75.0)$ & \\
\hline \multicolumn{4}{|l|}{ Smoking Status } \\
\hline Current smoker & $345(30.7)$ & 1945(33.7) & \multirow{3}{*}{0.1091} \\
\hline Former smoker & $514(45.7)$ & 2573(44.6) & \\
\hline Non-smoker & $266(23.6)$ & $1254(21.7)$ & \\
\hline \multicolumn{4}{|l|}{ Body Mass Index (BMI, $\mathrm{kg} / \mathrm{m}^{2}$ ) } \\
\hline Underweight $(<18.5)$ & $86(7.6)$ & $358(6.2)$ & \multirow{5}{*}{$<0.0001$} \\
\hline Normal & $281(24.9)$ & $1631(28.1)$ & \\
\hline Overweight & $276(24.4)$ & $1749(30.2)$ & \\
\hline Obese & $368(32.5)$ & $1621(28.0)$ & \\
\hline Morbidly obese & $120(10.6)$ & $440(7.6)$ & \\
\hline Health Coverage & $1033(91.7)$ & $5321(92.0)$ & 0.7456 \\
\hline Could Not See Doctor Because of Cost & 263(23.4) & 962(16.7) & $<0.0001$ \\
\hline Exercise & $465(41.3)$ & $3209(55.4)$ & $<0.0001$ \\
\hline Disability & $893(79.0)$ & $3508(60.9)$ & $<0.0001$ \\
\hline
\end{tabular}




\section{Table 2.The Prevalence of Comorbidities Among the COPD Patients Who Visited or Did Not Visit an Emergency Department or Hospital in the Previous Year}

\begin{tabular}{lcrl} 
Comorbidities & $\begin{array}{c}\text { Hospitalization/ No Hospitalization/ } \\
\text { ED Visits } \\
\text { (N= 1131) }\end{array}$ & $\begin{array}{c}\text { Nalue } \\
\text { ED Visits } \\
\text { (N=5799) }\end{array}$ & \\
\hline Myocardial Infarction & $299(26.7)$ & $1029(17.9)$ & $<0.0001$ \\
\hline Coronary Heart Disease & $340(30.7)$ & $1121(19.8)$ & $<0.0001$ \\
\hline Stroke & $188(16.7)$ & $642(11.2)$ & $<0.0001$ \\
\hline Cancer & $248(22.0)$ & $1033(17.9)$ & 0.0001 \\
\hline Arthritis & $802(71.5)$ & $3698(64.1)$ & 0.0032 \\
\hline Depression & $523(46.7)$ & $2068(35.8)$ & $<0.0001$ \\
\hline Kidney Disease & $136(12.1)$ & $475(8.3)$ & 0.0004 \\
\hline Diabetes & $325(29.7)$ & $1319(23.6)$ & 0.0122 \\
\hline Asthma & $569(48.5)$ & $1955(32.9)$ & $<0.0001$ \\
\hline
\end{tabular}

factor for hospitalization, ${ }^{14}$ our study found that the patients presenting for ED visits or hospitalization were younger. The large power associated with the BRFSS dataset allowed small differences in age to be statistically significant; however, the fact that young individuals make up a significant percentage of this COPD cohort has been shown in other studies. ${ }^{15-17}$ Although older individuals may have a higher risk of admission to the hospital, we speculate that younger individuals are more likely to visit an emergency department for less severe exacerbations of symptoms. Unfortunately, the BRFSS does not contain data that could clarify linkages between ED use and hospital admissions.

Gender was not associated with a higher risk for ED visits or hospitalization as has been seen in previous studies ${ }^{17,18}$ Although some studies have found that female sex is a protective factor for ED visits or hospitalization, ${ }^{15}$ other studies have found higher ED visits or hospitalization rates. ${ }^{19}$ As the difference in tobacco use between sexes continues to narrow ${ }^{20}$ and we recognize that women share the burden of smokingrelated disease with men; this finding is not unexpected.

Surprisingly, no differences in tobacco use were found between the cohorts. Tobacco smoking is considered to be one of the most important factors associated with COPD-related hospitalizations, worse outcomes, and comorbid conditions such as cardiovascular disease. As current smoking trends have reduced since $1965,{ }^{1}$ other risk factors such as exposure to air pollution, secondhand smoke, occupational dust, chemicals and hereditary conditions may play an increasingly significant role. ${ }^{21}$ Tobacco cessation counseling should be addressed during each encounter with the patient. However, the data suggests that issues related to health care access should transition to a top priority.

Socioeconomic status starting early in life plays an important role affecting the risk of developing COPD independent of smoking and gender. $^{22}$ As has been seen in other studies, education, income, and employment were inversely associated with ED visits or hospitalization. ${ }^{19}$ Being married was found more often in the cohort without ED visits or hospitalization. ${ }^{5,23,24}$ The relationship of socioeconomic status with ED visits or hospitalization is likely complex. Although more smoking, more occupational exposure to dust and fumes, and more secondhand smoke may influence disease pathogenesis, ${ }^{25,26}$ less contact with health care, more obesity, and less exercise are demographics that are amenable to interventions. ${ }^{27}$ Since we speculate that many of these disparities were associated with ED presentations, alternative interventions to provide social support, improve home environmental triggers of exacerbations, and improve alternative models of health care delivery and medications should be studied.

Interestingly, we found that many of the patients with COPD were not inclined to visit a physician despite having health insurance. Although 91.7\% were covered by health insurance, $23.7 \%$ could not see a doctor because of the financial difficulties. The impact of high insurance deductibles, residual medical debt, ${ }^{28}$ or medication costs on COPD care remain understudied barriers to care. Since regular COPD medication use prevents exacerbations, this finding requires a reassessment of health care delivery in COPD populations.

Low physical activity was found to be an independent risk factor for ED visits or hospitalization. ${ }^{29}$ Our finding 
is consistent with other studies. Since pulmonary rehabilitation within 1 month of hospital discharge is associated with less re-hospitalization, ${ }^{30}$ there is uncertainty whether the benefits with exercise occur in domains of physiology (improved muscle mitochondrial oxidative capacity and less $\mathrm{CO}_{2}$ production), improved medication compliance, improved mucus clearance, or other factors. $^{31}$

In our study, extremes of BMI are associated with higher ED visits or hospitalization. Low BMI was associated with emergency care needs, consistent with other studies. ${ }^{15,18,32,33}$ In other studies, a high BMI has been associated with increased risk of death, in part associated with the higher prevalence of comorbidities. ${ }^{34}$ This suggests that comorbidities play an important role in the outcome of COPD. Data on the morbidly obese COPD patient is very scarce. Our study suggests that these patients are at the highest
Figure 3. ED Visits/Hospitalization and Comorbidities

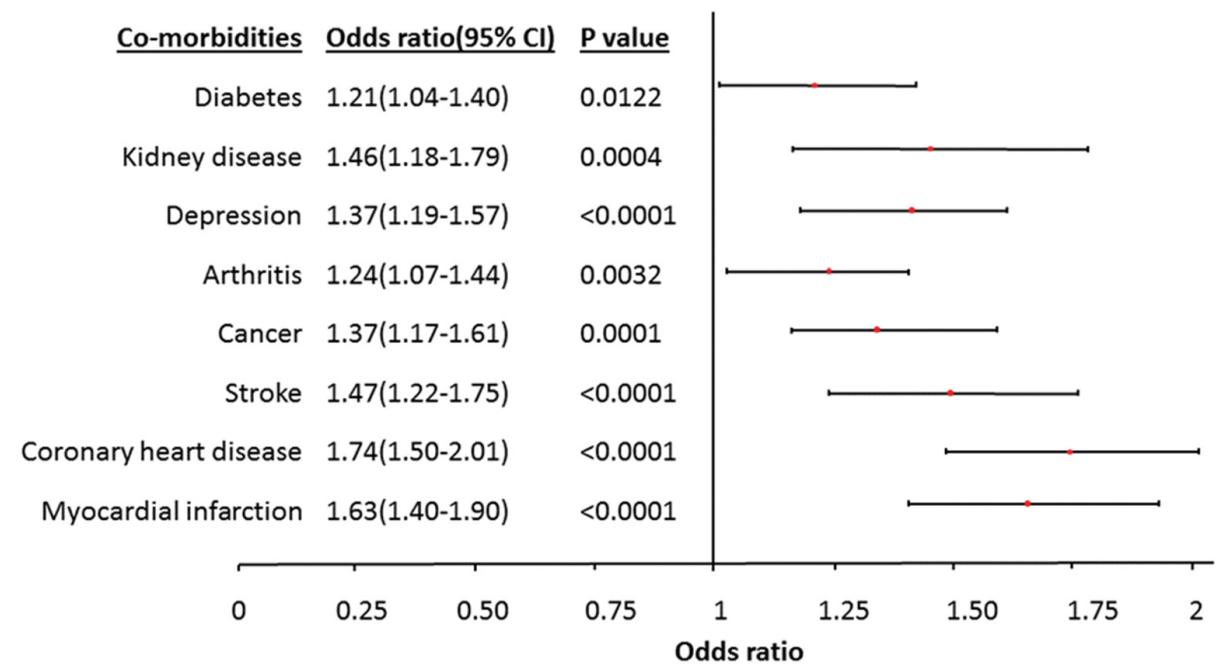

The risks of comorbidities are higher in those who had ED visits or hospitalization compared to those without. risk of ED visits or hospitalization. An observational study from the National Health and Nutritional Examination Survey III reported that these individuals die of unknown respiratory causes. ${ }^{35}$ As morbidly obesity increases in prevalence, these individuals with COPD should be studied carefully to better understand this observation.

The group of COPD patients with ED visits or hospitalization had higher proportions of patients with comorbidities compared to those without. Similar to other studies, ${ }^{36}$ cardiovascular disease (CVD) was a frequent comorbidity. In a retrospective cohort study, it was found that patients with comorbid COPD and CVD had twice the risk of a COPD-related hospitalization compared to patients without comorbid CVD. ${ }^{37}$ This study

\section{Figure 4. ED Visits/Hospitalization and Body Mass Index}

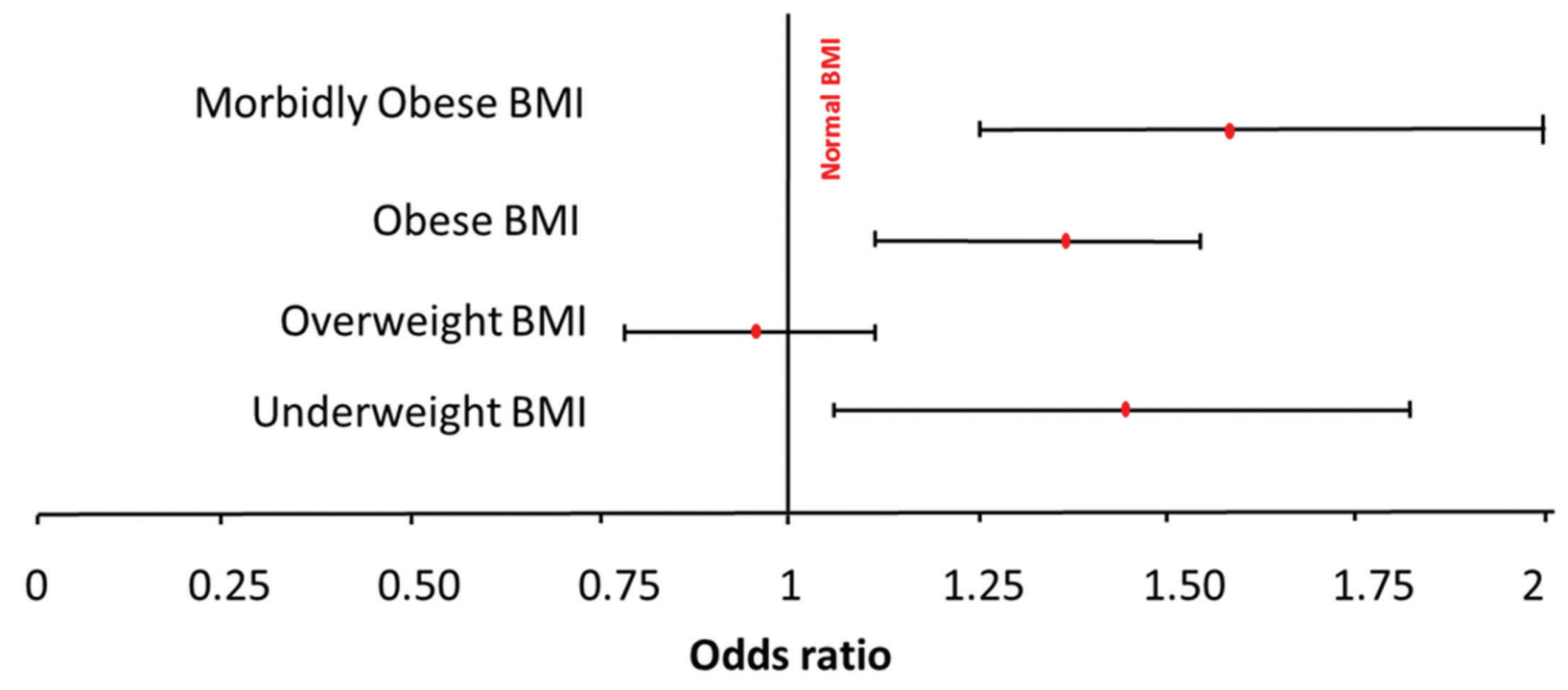

Underweight, obese, and morbidly obese COPD patients have more ED visits or hospitalization compared to COPD patients with a normal BMI. 
shows similar findings and may impact unplanned readmissions. ${ }^{38}$ However, the breadth of comorbidity differences between the 2 cohorts is also impressive for disease states that range from cancer to depression. ${ }^{39}$ This study cannot define the cause of ED visits or hospitalization. However, a focus on comprehensive care of the chronically-ill COPD patient who presents to emergency care likely will be needed to make an impact on health.

There were some limitations to this study including those associated with the BRFSS survey methodology. 2,40 First, information on symptom severity and pulmonary function testing were not available. Even though we did not have lung function tests, the BRFSS inquires whether lung function testing has been performed. We analyzed the data using only those individuals who had lung function tests finding few differences (data not shown). Second, due to its cross-sectional design, the study shows associations but does not identify causal relationships. The finding that these patients are younger raises the question of whether asthma or an asthma COPD overlap syndrome was present. Table 2 shows that some individuals who were diagnosed with COPD by a physician and eligible for this study, also answered that they had asthma. Third, data regarding the reason for the hospital visit is not available, although the question implies a respiratory cause. However, this deficiency is minor compared to the ability of the BRFSS to provide a population-based snapshot of the emergency care-seeking COPD patient.

\section{Conclusions}

In conclusion, the COPD modules of the BRFSS have provided a unique opportunity to characterize the COPD populations using emergency care in the United States. Our study exemplifies current efforts to analyze and report population-based, COPD-related public health data, a major goal of the CDC. ${ }^{41}$ COPD patients with lower socio-economic status, extremes of BMI, more disabilities, and frequent comorbidities were independently associated with COPD ED visits or hospitalization. The study also suggests that opportunities to improve health care access, increase pulmonary rehabilitation utilization, and address COPD comorbidities will be needed to better manage COPD patients using emergency services.

\section{Declaration of Interest}

Drs. Suchit Kumbhare, Tatsiana Beiko, and Susan R. Wilcox do not have conflicts of interest. Dr. Charlie Strange has current, past, or pending grants in COPD from the Alpha-1 Foundation, Baxter, CSL Behring, Entera Health, Grifols, and the National Institutes of Health. He consults for AstraZeneca, BoehringerIngelheim, CSL Behring, Grifols, PlasmaTech, PneumRx, Pulmonx, and Uptake Medical on COPD. 


\section{References}

1. Global initiative for chronic Obstructive Lung Disease (GOLD). Global strategy for diagnosis, management, and prevention of COPD (update 2015). GOLD website. http://www.goldcopd. com/ Published 2015. Accessed November 29, 2015.

2. Powell-Griner E, Centers for Disease Control and Prevention. Uses and limitations of the behavioral risk factor surveillance system data. American Statistical Association website. https:// www.amstat.org/sections/srms/Proceedings/papers/1998_033. pdf Published 1998. Accessed November 29, 2015.

3. Menezes AMB, Perez-Padilla R, Jardim JRB, et al, Chronic obstructive pulmonary disease in five Latin American cities (the PLATINO study): a prevalence study. Lancet. 2005; 366(9500): 1875-1881.

doi: http://dx.doi.org/10.1016/S0140-6736(05)67632-5

4. Guarascio AJ, Ray SM, Finch CK, Self TH. The clinical and economic burden of chronic obstructive pulmonary disease in the USA. Clinicoecom Outcomes Res. 2013; 5: 235-245.

5. Yeatts KB, Lippmann SJ, Waller AE, et al. Population-based burden of COPD-related visits in the ED: return ED visits, hospital admissions, and comorbidity risks. Chest. 2013; 144(3): 784-793. doi: http://dx.doi.org/10.1378/chest.12-1899

6. Donaldson GC, Wedzicha JA. COPD exacerbations-1: Epidemiology. Thorax. 2006; 61(2): 164-168. doi: http://dx.doi.org/10.1136/thx.2005.041806

7. Sullivan SD, Ramsey SD, Lee TA. The economic burden of COPD. Chest. 2000. 117(2 Suppl): 5S-9S.

doi: http://dx.doi.org/10.1378/chest.117.2_suppl.5S

8. Shi L, Samuels ME, Pease M, Bailey WP, Corley EH. Patient characteristics associated with hospitalizations for ambulatory care sensitive conditions in South Carolina. South Med J. 1999; 92(10): 989-998.

doi: http://dx.doi.org/10.1097/00007611-199910000-00009

9. O'Neil SS, Lake T, Merrell A, Wilson A, Mann DA, Bartnyska LM. Racial disparities in hospitalizations for ambulatory caresensitive conditions. Am J Prev Med. 2010; 38(4): 381-388. doi: http://dx.doi.org/10.1016/j.amepre.2009.12.026

10. Cavaillès $A$, Brinchault-Rabin G, Dixmier A, et al. Comorbidities of COPD. Eur Respir Rev. 2013. 22(130): 454-475.

doi: http://dx.doi.org/10.1183/09059180.00008612

11. Donaldson G, Seemungul TAR, Bhowmik A, Wedzicha JA, et al. Relationship between exacerbation frequency and lung function decline in chronic obstructive pulmonary disease. Thorax. 2002. 57(10): 847-852. doi: http://dx.doi.org/10.1136/thorax.57.10.847

12. Kashihara D Carper K, Medical Expenditure Panel Survey. National health care expenses in the U.S. civilian noninstitutionalized population, 2009-Statistical Brief \#355. Agency for Healthcare Research and Quality website. Published January 2012. Accessed November 2015.
13. Soler-Catalu-a JJ, Martinez-Garcia MA, Sanchez PR, Salcedo E, Navarro M, Ochando R. Severe acute exacerbations and mortality in patients with chronic obstructive pulmonary disease. Thorax. 2005; 60(11): 925-931.

doi: http://dx.doi.org/10.1136/thx.2005.040527

14. Gadoury, MA, Schwartzman K, Rouleau M, et al. Selfmanagement reduces both short- and long-term hospitalisation in COPD. Eur Respir J. 2005; 26(5): 853-857.

doi: http://dx.doi.org/10.1183/09031936.05.00093204

15. Kessler R, Faller M, Fourgaut G, Mennecier B, Weitzenblum E. Predictive factors of hospitalization for acute exacerbation in a series of 64 patients with chronic obstructive pulmonary disease. Am J Respir Crit Care Med. 1999; 159(1):158-164. doi: http://dx.doi.org/10.1164/ajrccm.159.1.9803117

16. Seemungal TAR, Donaldson GC, Paul EA, Bestall JC, Jefferies DJ, Wedzicha JA. Effect of exacerbation on quality of life in patients with chronic obstructive pulmonary disease. Am J Respir Crit Care Med. 1998; 157(5): 1418-1422. doi: http://dx.doi.org/10.1164/ajrccm.157.5.9709032

17. Osman IM, Godden DJ, Friend JA, Legge JS, Douglas JG. Quality of life and hospital re-admission in patients with chronic obstructive pulmonary disease. Thorax. 1997; 52(1):67-71. doi: http://dx.doi.org/10.1136/thx.52.1.67

18. Garcia-Aymerich J, Monsó E, Marrades RM, et al. Risk factors for hospitalization for a chronic obstructive pulmonary disease exacerbation-- EFRAM study. Am J Respir Crit Care Med. 2001; 164(6): 1002-1007.

doi: http://dx.doi.org/10.1164/ajrccm.164.6.2006012

19. Trachtenberg AJ, Dik N, Chateaur D, Katz A. Inequities in ambulatory care and the relationship between socioeconomic status and respiratory hospitalizations: a population-based study of a Canadian city. Annals Fam Med. 2014; 12(5): 402-407. doi: http://dx.doi.org/10.1370/afm.1683

20. Centers for Disease Control and Prevention. Current cigarette smoking among adults-United States, 2005-2014. MMWR Morb Mortal Wkly Rep. 2015; 64(44):1233-1240. Centers for Disease Control website. http://www.cdc.gov/mmwr/preview/ mmwrhtml/mm6444a2.htm Published November 13, 2015. Accessed December 8, 2015.

21. Eriksson S. Pulmonary emphysema and alpha-1 antitrypsin deficiency. Acta Med Scand. 1964. 175:197-205. doi: http://dx.doi.org/10.1111/j.0954-6820.1964.tb00567.x

22. Prescott E, Lange P, Vestbo J. Socioeconomic status, lung function and admission to hospital for COPD: results from the Copenhagen City Heart Study. Eur Respir J. 1999;13(5): 11091114. doi: http://dx.doi.org/10.1034/j.1399-3003.1999.13e28.x 
23. Hasegawa K, Tsugawa Y, Tsai C-L, Brown DFM, Carmargo Jr CA. Frequent utilization of the emergency department for acute exacerbation of chronic obstructive pulmonary disease. Respir Res. 2014. 15(1): 40-40. doi: http://dx.doi.org/10.1186/1465-9921-15-40

24. Tsai C-L, Griswold SK, Clark S, Carmargo Jr CA. Factors associated with frequency of emergency department visits for chronic obstructive pulmonary disease exacerbation. J Gen Intern Med. 2007; 22(6): 799-804. doi: http://dx.doi.org/10.1007/s11606-007-0191-7

25. Pauwels RA, Buist S, Calverley PMA, Jenkins CR, Hurd SS. Global strategy for the diagnosis, management, and prevention of chronic obstructive pulmonary disease. NHLBI/ WHO Global Initiative for Chronic Obstructive Lung Disease (GOLD) Workshop summary. Am J Respir Crit Care Med. 2001. 163(5):1256-1276.

doi: http://dx.doi.org/10.1164/ajrccm.163.5.2101039

26. Lange P, Marott JL, Vestbo J, Sylvan I, Nordestgaard BG. Socioeconomic status and prognosis of COPD in Denmark. COPD. 2014; 11(4): 431-437.

doi: http://dx.doi.org/10.3109/15412555.2013.869580

27. Steenland, K, Henley J, Thun M. All-cause and cause-specific death rates by educational status for two million people in two American Cancer Society cohorts, 1959-1996. Am J Epidemiol. 2002; 156(1):11-21. doi: http://dx.doi.org/10.1093/aje/kwf001

28. New survey findings: 79 million U.S. adults have medical bill problems or are paying off medical debt; low and moderate income families hit hardest [news release]. New York, NY: The Commonwealth Fund; August 20, 2008. http://www. commonwealthfund.org/publications/press-releases/2008/aug/ new-survey-findings--79-million-u-s--adults-have-medical-billproblems-or-are-paying-off-medical-deb Accessed November 2015.

29. Bahadori K, FitzGerald JM. Risk factors of hospitalization and readmission of patients with COPD exacerbation - systematic review. Int J Chron Obstruct Pulmon Dis. 2007. 2(3): 241-251.

30. Seymour JM, Moore L, Jolley CJ, et al. Outpatient pulmonary rehabilitation following acute exacerbations of COPD. Thorax. 2010; 65(5):423-428.

doi: http://dx.doi.org/10.1136/thx.2009.124164

31. Spruit MA, Singh SJ, Garvey C, et al. An official American Thoracic Society/European Respiratory Society Statement: Key concepts and advances in pulmonary rehabilitation. Am J Respir Crit Care Med. 2013;188(8):1011-1027.

32. Hallin R, Gudmundsson G, Ulrik CS, et al. Nutritional status and long-term mortality in hospitalised patients with chronic obstructive pulmonary disease (COPD). Respir Med. 2007. 101(9):1954-1960.

doi: http://dx.doi.org/10.1016/j.rmed.2007.04.009
33. Liu Y, et al. Body mass index, respiratory conditions, asthma, and chronic obstructive pulmonary disease. Respir Med. 109(7): p. 851-859.

doi: http://dx.doi.org/10.1016/j.rmed.2015.05.006

34. Divo MJ, Cabrera C, Casanova C, et al. Comorbidity distribution, clinical expression and survival in COPD patients with different body mass index. Chronic Obstr Pulm Dis (Miami). 2014;1(2): 229-238. doi: http://dx.doi.org/10.15326/jcopdf.1.2.2014.0117

35. Jordan Jr JG, Mann JR. Obesity and mortality in persons with obstructive lung disease using data from the NHANES. South Med J. 2010;103(4):323-330.

http://dx.doi.org/10.1097/SMJ.0b013e3181d394b4

36. Feary JR, Rodrigues LC, Smith CJ, Hubbard RB, Gibson JE. Prevalence of major comorbidities in subjects with COPD and incidence of myocardial infarction and stroke: a comprehensive analysis using data from primary care. Thorax. 2010; 65(11): 956962. doi: http://dx.doi.org/10.1136/thx.2009.128082

37. Dalal AA, Shah M, Lunacsek O, Hanania NA. Clinical and economic burden of patients diagnosed with COPD with comorbid cardiovascular disease. Respir Med. 2011. 105(10): 1516-1522. doi: http://dx.doi.org/10.1016/j.rmed.2011.04.005

38. Yu T-C, Zhou H, Suh K, Arcona S. Assessing the importance of predictors in unplanned hospital readmissions for chronic obstructive pulmonary disease. Clinicoecon Outcomes Res. 2015; 7:37-51. doi: http://dx.doi.org/10.2147/CEOR.S74181

39. Hanania NA, Millerova H, Locantore NW, et al. Determinants of depression in the eclipse chronic obstructive pulmonary disease cohort. Am J Respir Crit Care Med. 2011;183(5):604-611. doi: http://dx.doi.org/10.1164/rccm.201003-0472OC

40. Centers for Disease Control and Prevention (CDC). Behavioral Risk Factor Surveillance System: Comparability of Data BRFSS 2012. CDC website. http://www.cdc.gov/brfss/ual_data/2012/ pdf/compare_2012.pdf . Published July 15, 2013. Accessed November 29, 2015.

41. Centers for Disease Control and Prevention. Public Health Strategic Framework for COPD Prevention. Atlanta, GA: Centers for Disease Control and Prevention; 2011. http://www.cdc.gov/ copd/pdfs/Framework_for_COPD_Prevention.pdf Accessed November 29, 2015. 